\title{
An Overview of the Impact of Climate Change on Pathogens, Pest of Crops on Sustainable Food Biosecurity
}

\author{
Mbong Annih Grace ${ }^{1}$, Tembe-Fokunang Estella Achick², Berinyuy Eustace Bonghan ${ }^{6}$, \\ Manju Evelyn Bih ${ }^{1}$, Ngo Valery Ngo ${ }^{3}$, Mbah James Ajeck ${ }^{4}$, Galega Tangham Bobyiga Prudence ${ }^{5}$, \\ Fokunang Charles Ntungwen ${ }^{2, *}$ \\ ${ }^{1}$ Department of Plant Science, Faculty of Science, University of Dschang, Dschang, Cameroon \\ ${ }^{2}$ Department of Pharmaco-toxicology and Pharmacokinetics, Faculty of Medicine \& Biomedical Sciences, University of Yaoundé 1, \\ Yaounde, Cameroon \\ ${ }^{3}$ Department of Global Health, School of Public Health and Community Medicine, Institute of Medicine, Sahlgrenska Academy, University \\ of Gothenburg, Gothenburg, Sweden \\ ${ }^{4}$ Department of Chemistry, Faculty of Science, University of Buea, Buea, Cameroon \\ ${ }^{5}$ Department of Climate Change, Biodiversity and Conservation, Secretariat General, Ministry of Environment, Protection of Nature, \\ Yaoundé, Cameroon \\ ${ }^{6}$ Department of Biochemistry, Faculty of Medicine \& Biomedical Sciences, University of Yaoundé 1, Yaounde, Cameroon
}

Email address:

charlesfokunang@yahoo.co.uk (F. C. Ntungwen)

${ }^{*}$ Corresponding author

\section{To cite this article:}

Mbong Annih Grace, Tembe-Fokunang Estella Achick, Berinyuy Eustace Bonghan, Manju Evelyn Bih, Ngo Valery Ngo, Mbah James Ajeck, Galega Tangham Bobyiga Prudence, Fokunang Charles Ntungwen. An Overview of the Impact of Climate Change on Pathogens, Pest of Crops on Sustainable Food Biosecurity. International Journal of Ecotoxicology and Ecobiology. Vol. 4, No. 4, 2019 , pp. 114-124. doi: $10.11648 /$ j.ijee. 20190404.15

Received: October 25, 2019; Accepted: December 2, 2019; Published: December 10, 2019

\begin{abstract}
Anthropogenic activities on the environment have intensified in the last century resulting in a devastating increase in greenhouse gases and triggering global climate oscillation. Global food productions have increase significantly by $50 \%$ in order to meet the anticipated demand of the world's population by 2050. The challenges of food production increases are high and even harder if climate change as a global threat is not addressed. In the coming years, there could be more changes in the biosecurity of food crops due to escalating global climate change. The effects of climate change on plant pathogens and the diseases they cause have been reported in some pathosystems. Climatic changes have been predicted to affect pathogen development and survival rates with possible modification of host susceptibility, host-pathogen-vector interaction that could lead to changes in the impact of diseases on food crops. The climate change may affect not only the optimal conditions for infection but also host specificity and mechanisms of plant infection. Changes in the abiotic conditions are known to affect the microclimate surrounding plants and the susceptibility of plants to disease. These changing conditions are expected to affect microbial communities in the soil and canopy pathosystems, with the possibility of altering the beneficial effects of these communities. Since both the pathogens and host plants could be affected by the dramatic changes in the magnitude of disease expression in a given pathosystem, the geographical distribution of particular plant diseases, their economic importance in a given location, and the set of diseases that infect each crop are crucial to understand their etiology and level of virulence. These changes could affect the measures farmers take to efficiently manage these diseases, as well as the feasibility of cropping systems in particular regions. This review examines the effects of changes in temperature, $\mathrm{CO}_{2}$ and ozone concentrations, precipitation, and drought on the biology of pathogens and their ability to infect plants and survival in natural and agricultural environments. We also underpin the multiple aspects linked to the effects of climate change on crop plant diseases, including the impact of increasing concentrations of atmospheric $\mathrm{CO}_{2}$ and other gases, and how diseases can change under the alteration of atmospheric gases conditions in the future.
\end{abstract}


Keywords: Food Biosecurity, Crop Loss, Pathosystems, Disease Management, Climate Change, Atmospheric $\mathrm{CO}_{2}$

\section{Introduction}

The concentrations of atmospheric greenhouse gases are being altered by human activities leading to global climate change. These activities, including the burning of fossil fuel and deforestation, intensified after the industrial revolution at the end of the eighteenth century $[1,2]$. The atmospheric concentration of carbon dioxide $\left(\mathrm{CO}_{2}\right)$ has reached levels significantly higher than in the last 650 thousand years [3, 4]. Since 2000, the growth rate in $\mathrm{CO}_{2}$ concentration is increasing more rapidly than in the previous decades [1, 5-6]. A similar occurrence has been observed for methane $\left(\mathrm{CH}_{4}\right)$, Nitrous oxide $\left(\mathrm{N}_{2} \mathrm{O}\right)$, and other greenhouse gases [3, 7-8]. Several changes in the climate have been registered. The average global surface temperature has increased by $0.2^{\circ} \mathrm{C}$ per decade in the past 30 years $[5,9]$. Eleven of the twelve warmest years ever registered by instruments since 1850 occurred between 1995 and 2006 except 1996. The alterations in the water cycle have also been observed. These changes will probably continue to happen even if greenhouse gas concentrations stabilize due to the system's thermal inertia and to the long period necessary for returning to a lower equilibrium $[3,10]$.

Anthropogenic activities have a significant impact on the climate and the ecosystems, resulting in a continuous increase in temperatures, changes in the quantity and pattern of precipitation, increased $\mathrm{CO}_{2}$ and ozone levels, and drought. Any change in ecosystems can affect plant diseases because these diseases result from an interaction between a susceptible plant, a virulent pathogen, and the environment [11]. Losses of marketable yield in crops and reduction in growth and productivity of tree species are observed after exposure to high levels of $\mathrm{O}_{3}$, and while pollutants can influence plant pathogens, foliar pathogens can also affect the leaf response to $\mathrm{O}_{3}$. Some aspects associated with climate changes, such as the increase of temperature and changes in precipitation and moisture can have some effects on the fitness (number of generations, the sexual reproduction) of plant pathogens, extending the amount of time available for their reproduction and dissemination $[1,12]$.

\section{Climate Change and Disease Management}

Plant disease management still depends on the integrated use of fungicides, although other alternative methods are still under study. The persistence of a chemical on the plant surfaces depends on weather conditions in particular precipitation and temperature. Changes in duration, frequency, and intensity of rain events alter the efficacy of fungicides since they can be quickly washed away. The temperature influences the degradation of pesticides and alters the morphology and physiology of plants affecting their penetration, translocation, and mode of action [13]. Evidence of increased aggressiveness at higher temperatures of some pathogens has been reported, suggesting that they can adapt to and benefit from higher temperatures. An example include when the fungus Monilinia fructicola spread in several European countries, $M$ laxa and $M$ fructigena were the only pathogens responsible for brown rot in stone and pome fruits in Europe [2, 14]. The reason for its dissemination could be attributed to a faster capacity to growth at a higher temperature than the other two Monilinia species.

Other essential aspects concern the influence of climate change on the biology of the host and indirectly its response to pathogen attacks; for example, higher temperatures produce an extension of the vegetative season and the consequent increase of secondary infections on leaves [1516]. The persistence of a fungicide on the plant depends on weather conditions such as precipitation and temperature, changes in duration, frequency, and intensity of rain events can alter the efficacy of the chemicals. It has been reported that those climatic factors that affect food crop production are interrelated. These factors include the farming practice within a community, crop pest and disease status, the development and improvement of new cultivars or transgenic genotypes with resistant agronomic/genetic traits, organic farming and soil status as indicated in Figure 1.

\section{Impact of Factors Influencing Crop Production}

There are many diversified factors that have been reported to influence crop production in developed and low income economies as indicated in figure 1. Climate change, status of the crop in terms of pest infestation and diseases, farming practices contributes more in the sustainable food crop production in sub Saharan Africa [20]. Climate change has a great influence on post-harvest crop quality due to the fact that post-harvest technology of transformation of harvested products is still at its infancy in developing countries such as Cameroon in particular and the sub Saharan Africa in general [3, 7, 17].

\section{Impact on factors influencing crop production}

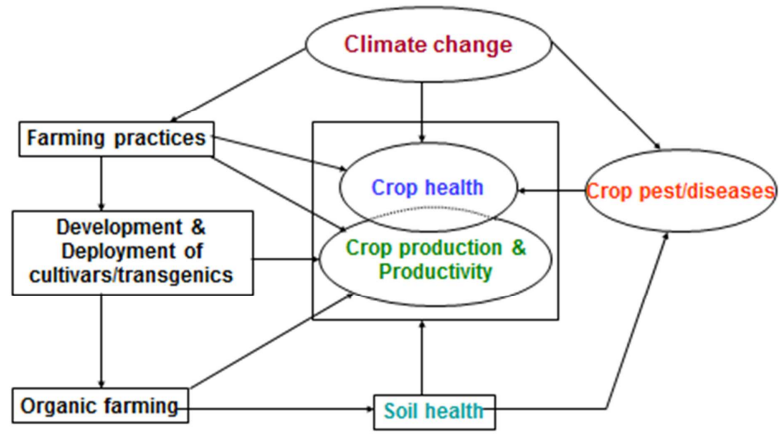

11

Figure 1. Impact on factors influencing crop production [20]. 
In Phyto-pathology, the environment is considered as the combination of temperature, humidity, precipitation, ultraviolent (UV)-rays. Water, air, and soil, is the environmental factor which constitutes one of the three sides of the disease triangle [9]. This environment can significantly influence the incidence severity of plant diseases $[11,16,17]$ In the Anthropocene era, the recent period of the history of the earth, human activities have had a significant impact on climate change and ecosystems, resulting in increased temperature, changes in the quantity and pattern of precipitation, increased $\mathrm{CO}_{2}$ and ozone levels, drought [1820]. Increase in $\mathrm{CO}_{2}$ levels tends to reduce damage caused by high ozone concentrations [7]

\subsection{Climate Changes and Pathogens}

Climate change can lead to remarkable losses in crop yield, reduction in growth, and productivity of tree species as a result of high levels of $\mathrm{O}_{3}$, pollutants [4, 21]. This effect can influence plant pathogens, and foliar pathogens can affect the leaf responses to $\mathrm{O}_{3}$. Generally, ozone exposure tends to decrease the incidence of disease caused by obligate parasites while increasing the frequency of diseases caused by facultative parasites as shown in table 1 .

Table 1. Effect of ozone on some fungal plant diseases [15].

\begin{tabular}{lll}
\hline Fungi & Host plant & Effect on disease \\
\hline Obligate biotrophs & & \\
Puccinia graminis f.sp tritici & Wheat & Decreased hyphal growth and urediospore \\
Erysiphe graminis f.sp hordei & Barley & production on $\mathrm{O}_{3}$ injured leaves. \\
Necrotrophs & Potato & Infection only in $\mathrm{O}_{3}$ injured leaves. \\
Botrytis cinerea & Pine & Increased severity of needle blight \\
Lophodermium $s p$ & & \\
\hline
\end{tabular}

In general, necrotrophic and biotrophic pathogens show a different behaviour concerning their nutrition. The first obtain nutrients from dead tissues, while the second derive nutrients from living cells and maintain a prolonged and deep interaction with their host $[22,23]$. Therefore, all climatic factors that cause or accelerate tissue death, high temperatures, or $\mathrm{O}_{3}$ levels, could favour necrotrophic pathogens. Moreover, climatic factors that stimulate plant growth, such as elevated levels of $\mathrm{CO}_{2}$ or increased temperature, could likely change the physiology of the plant, altering host colonization by biotrophic pathogens [11, 2425]. The decomposition of high $\mathrm{CO}_{2}$ litter occurs at a low rate, increasing the biomass availability, which combined with higher winter temperatures, might increase pathogen survival on crop residues, accumulating the amount of initial inoculum to infect subsequent crops $[4,26]$.

Today, the environment can influence host plant growth and susceptibility, pathogen reproduction, dispersal, survival and activity, as well as host-pathogen interaction. The classic disease triangle establishes the conditions for disease development, which is the interaction of a susceptible host, a virulent pathogen, and a favorable environment. This relationship is evidenced in the definition of plant disease itself. A plant disease is a dynamic process in which a host and a pathogen intimately related to the environment are mutually influenced, resulting in morphological and physiological changes [27-29].

\subsection{Diseases Yield Losses}

Diseases are responsible for losses of at least $10 \%$ of global food production, representing a threat to food security estimated that annual losses by disease cost US\$220 billion $[1,30]$. Apart from the direct crop losses, the methods for disease control, especially the chemical methods, can result in environmental contamination and residual chemicals in food. Apart from social and economic problems, the close relationship between the environment and diseases suggests that climate change will cause modifications in the current phytosanitary scenario $[9,31]$. The impacts can be positive, negative, or neutral, since there can be a decrease, an increase, or no effect on the different pathosystems, in each region. The analysis of the potential impacts of climate change on plant diseases is essential for the adaptation measures, as well as for the development of resistant cultivars, new control methods, or adapted techniques to avoid more severe losses [9, 32-33]. Plant pathogens are ubiquitous in natural and managed systems, being among the first to demonstrate the effects of climate change due to the numerous populations, ease of reproduction and dispersal, and short time between generations. Plant pathogens, therefore, constitute a fundamental group of biological indicators that need to be evaluated regarding climate change impacts, besides being responsible for production losses, and potential threat to the agroecosystem sustainability [34].

\subsection{Geographical and Temporal Distribution}

The environment and diseases are closely related, and climate change plays a role in the alteration of the geographic and temporal distribution of phytosanitary problems. Pathogens and other microorganisms related to the disease process contribute to a rise in new diseases in certain regions, and other diseases may cease to be economically important, especially if the host plant migrates into new areas [35-37]. Pathogens tend to follow the host plant in its geographical distribution, but the rate at which pathogens become established in the new environment is a function of the mechanism of pathogen dispersal, suitability of the environment for dispersal, survival between seasons, and physiological and ecological changes in the host plant [14, 38]. Some very aggressive strains of pathogens with broad host range, such as Rhizoctonia, Sclerotinia, Sclerotium, and other necrotrophic pathogens can migrate from agroecosystems to natural vegetation, and less aggressive 
pathogens from natural plant communities can start causing damage in monocultures of nearby regions [39].

\section{Climate Change Risk Analysis}

Disease simulation models frequently used for forecasting can be utilized in simulation studies of spatial and temporal distribution in future climate scenarios. For vectortransmitted pathogens, the risk analysis may include the effects of climate change on the vector population, as reported by Evan et al. [16] for the barley yellow dwarf disease. One of the first studies about this subject was conducted by Boland et al [5]. Asian countries due to the importance cereal crops and to the losses related to diseases infections, caused by Magnaporthe grisea, simulations were made to study the risk of blast epidemics under the effects of temperature change and enhanced ultra violet radiation [40]. The results demonstrated that changes in the amount of rainfall do not affect the occurrence of the epidemics since they have little effect on the leaf wetting period. In cold subtropical zones, increased temperatures caused a rise in disease severity and in the area below the disease progress curve, because a higher risk of epidemics occurs under higher temperatures. In the humid tropical and warm subtropical zones, such as Southern China, Philippines, and Thailand, the opposite effect was observed [42-44].

Climate information Disease risk management

Climatic oscillation has become a global concern and a threat to food crop management to tame hunger worldwide. There are many actors, and advocacy initiatives in most countries to save the environment and increase food productivity. The initiative drive must be motivated by a well-developed climate information disease risk management system. There is the need for a high throughput data base system $[11,22]$. A model climate information-disease risk management system is illustrated in figure 2. This takes into account the historical climate data in a defined region, seasonal climate forecast, the different models for crop yield, crop-disease risk, plant disease model, the microclimate data and the economic input [7],

\section{Climate information-Disease risk management}

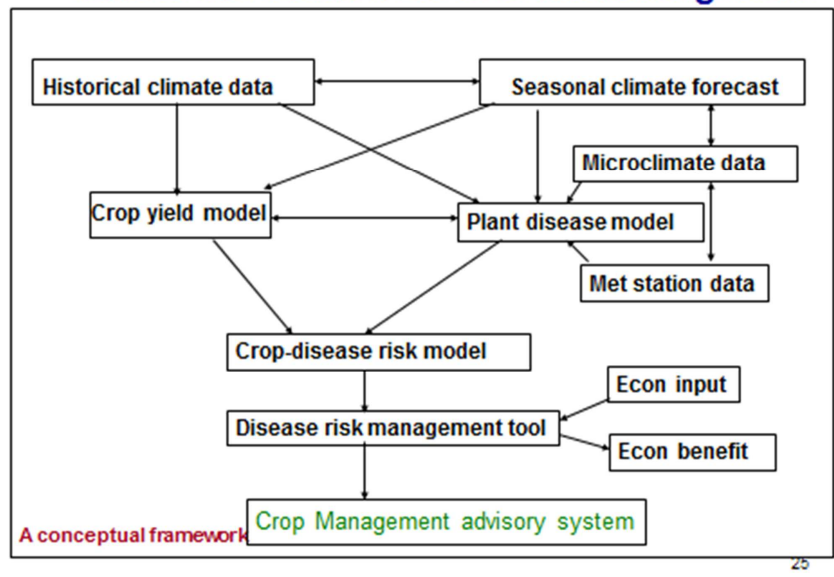

Figure 2. Climate information disease risk analysis management [7].
Lower temperatures increased the risk of rice blast epidemics since the current temperatures in these regions are above favourable values for the occurrence of this disease. However, a larger area below the disease progress curve does not always result in lower rice yield, since the effect in plant growth also takes place $[13,45,46]$.

Using mathematical models, Percy et al. [42] simulated climate change in Finland and concluded that warming would expand the cropping area for cereals by 2050 by 100 to 150 linear $\mathrm{km}$ per degree Celsius and increase in mean annual temperature. Moreover, higher yields are expected with higher $\mathrm{CO}_{2}$ concentrations. In this case, potato cropping will also be benefited with an estimated 20 to $30 \%$ increase in yield. A new distribution of the potato cyst nematode Globodera rostochiensis) is also predicted, with northward expansion in the country and a higher number of generations per year [15, 47]. In such a situation, the risk of potato blight caused by Phytophthora infestans is significantly higher in all regions of Finland [48]. Pellegrino et al studied the climate change risk analysis for the black sigatoka of banana caused by Mycosphaerella fijiensis and elaborated the disease distribution maps $[40,41]$. The maps revealed that there would be a reduction in the favourable area for the disease in Brazil.

\section{Atmospheric Carbon Dioxide}

There is a relatively large number of studies on the beneficial effect of increased concentration of atmospheric $\mathrm{CO}_{2}$ on plant growth. In the last few years, approximately 3,000 reports have been published on the subject [48-50]. High $\mathrm{CO}_{2}$ concentration supports plant growth, although there might be differences among species. $\mathrm{CO}_{2}$ enrichment promotes changes in plant metabolism, growth, and physiological processes. There is a significant increase in the photosynthetic rate and a decrease in the transpiration rate per unit leaf area, while total plant transpiration sometimes increases, due to the larger leaf area $[12,51]$. The alterations also include higher efficiency in the use of water and nitrogen by the plant [21]. The stimulus on photosynthesis is due to the reduction in competition between the atmospheric $\mathrm{CO}_{2}$ and $\mathrm{O}_{2}$ being fixed by the ribulose 1, 5-bisphosphate carboxylase-oxygenase (Rubisco) enzyme. The atmospheric concentration of $\mathrm{O}_{2}$ normally inhibits $\mathrm{CO}_{2}$ absorption by plants and triggers photorespiration. With a rise in $\mathrm{CO}_{2}$ concentration, the inhibition of photosynthesis by $\mathrm{O}_{2}$ tends to decrease due to an increase in the $\mathrm{CO}_{2}: \mathrm{Q}_{2}$ ratio $[11,52]$.

Despite shreds of evidences of the beneficial effects of $\mathrm{CO}_{2}$ on the host plant, it is not well known if these effects will still take place in the presence of pathogens or other limiting factors, particularly in tropical countries. Some studies have been conducted in controlled conditions, which might not reflect plant responses in the field, where there are variations and interactions among temperature, precipitation, and other factors $[25,53]$. The dynamics of crop diseases and pest influx are changing rapidly due to changing climate, and managing them has, therefore, become a huge challenge. Favourable atmospheric conditions have led to the 
appearance of entomopathogenic organisms, and new pests are more invasive to crops, as shown in figure 3, representing the negative effect of the rising levels of $\mathrm{CO}_{2}$ and temperatures on pests and diseases in crops.

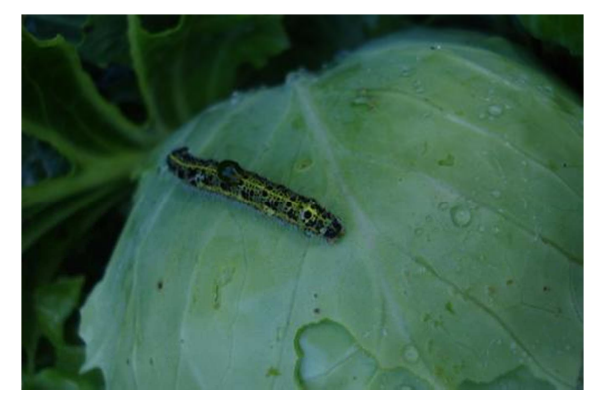

Figure 3. The negative effect of the rising levels of $\mathrm{CO}_{2}$ and temperatures on pests and diseases in crops [16].

Elevated $\mathrm{CO}_{2}$ can increase levels of simple sugars in leaves and lower their nitrogen content. These can increase the damage caused by many insects, who will consume more leaves to meet their metabolic requirements of nitrogen, and therefore, any attack will be more severe. Higher temperatures from global warming, mainly due to elevated $\mathrm{CO}_{2}$, will mean that more numbers of pests will survive the winter season [53]. Elevated $\mathrm{CO}_{2}$ will help in the overwintering of pathogens, while higher temperatures will favour thermophilic fungi [28, 54]. Higher temperatures could also lead to a poleward spread of many pests and diseases in both hemispheres and this will lead to more attacks over longer periods in the temperate climatic zone

Other possible effects of climate change need to be taken into account; on the one hand, the warmer temperature lowers the effectiveness of some pesticides, but on the other hand, it favours insect carriers of many disease pathogens and natural enemies of pests and diseases [55]. Therefore, depending on the pest or pathogen, elevated $\mathrm{CO}_{2}$ may act in a synergistic or opposing manner with higher temperatures. The results of such interactions are difficult to be anticipated, and thus, one is obliged to wait for visual signs of the appearance of a pest or disease before initiating action $[17,56]$.

The increase in plant biomass production, i.e., the increase in the production of shoots, leaves, flowers, and fruit, represents more tissue that can be infected by pathogens. Increased carbohydrate contents can stimulate the development of sugar-dependent pathogens, such as rusts and powdery mildews $[6,57]$. The increase in crop residues can represent better survival conditions for necrotrophic pathogens. The reduction in the stomatal opening can inhibit stomata-invading pathogens, such as rusts, downy mildew, and some necrotrophs [40]. The shortened growth period and accelerated ripening and senescence can reduce the infection period for biotrophic pathogens and increase the necrotrophic pathogen populations. The increase in root biomass increases the amount of tissue that could be infected by mycorrhiza or soil-borne pathogens but can compensate for the losses inflicted by the pathogens $[3,16]$. Higher root exudation can stimulate both pathogens and antagonistic microbiota in the rhizosphere (plant growth promoters).

Increased $\mathrm{CO}_{2}$ effects depend on insect-plant interaction such as increased carbon nitrogen in plants makes for poorer forage for insects, shift in plant defenses from nitrogen to carbon based, fewer toxins, tougher leaves, more tannins/ phenols, the deficiencies in micronutrients. The $\mathrm{CO}_{2}$ help for insects nitrogen addition for a better forage, shift in plant defenses from nitrogen to carbon based and consume more plant to make up for less nitrogen $[21,30]$

\subsection{Effect of Plant Pathogens Interactions as Indicators of Climate Change}

Disease forecasting models based on weather exist for many important plant diseases, and can be rescaled for other purposes such as climate change scenario analysis. Complexity in terms of the amount of information needed to adequately predict outcomes For example, predicting the effects of disease involves pathogen reproduction and dispersal, and multi-species interactions (in contrast to direct effects of weather on plant physiology) (Figure 4).

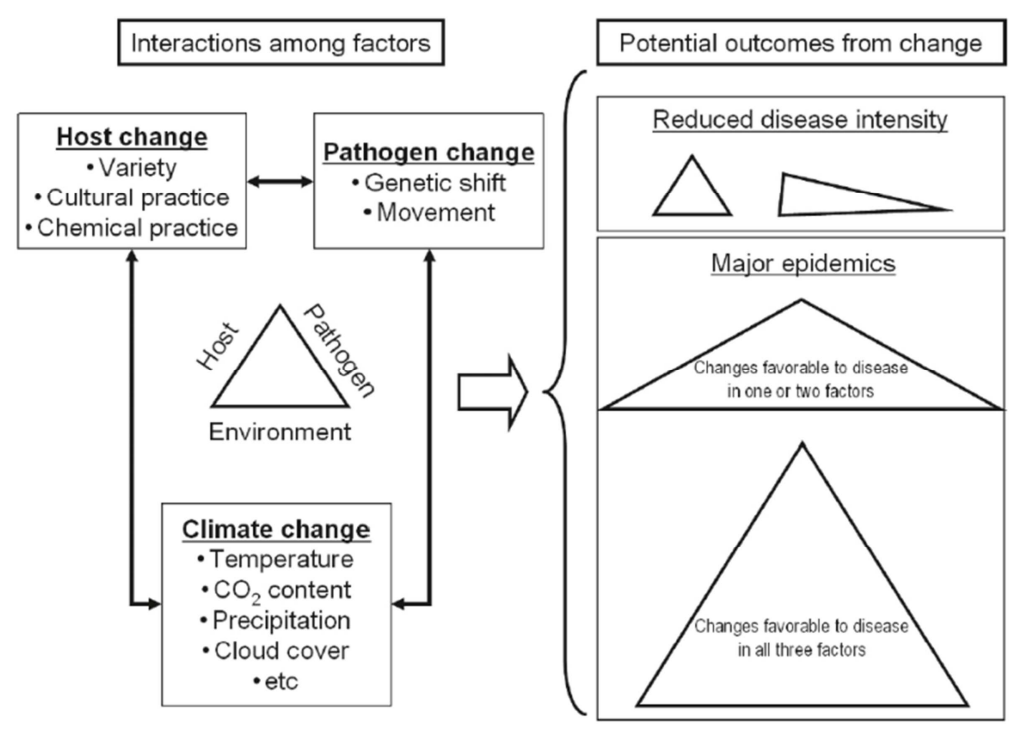

Figure 4. Effect of Plant pathogens interactions as indicators of climate change [25]. 


\subsection{Disease Management, Climate Change and Food Security}

All crop protection could be considered as an integrated approach since pesticides are directly applied only when there is a perceived threat. Such applications of the conventional crop protection products often disrupt the many processes controlling such organisms in some kind of benign balance in non-epidemic conditions.

\section{Disease Control}

Disease management strategies depend on climate conditions. Climate change will cause alterations in the disease geographical and temporal distributions, and consequently, the control methods will have to be adapted to this new reality [50]. Changes in temperature and precipitation can alter fungicide residue dynamics in the foliage, and the degradation of products can be modified. Alterations in plant morphology or physiology, resulting from growth in a $\mathrm{CO}_{2}$-enriched atmosphere or different temperature and precipitation conditions, can affect the penetration, translocation, and mode of action of systemic fungicides. Besides, those changes in plant growth can alter the period of higher susceptibility to pathogens, which can determine a new fungicide application calendar $[31,45,52]$. The fungicide market will undoubtedly change. Chen \& McCarl [12] performed a regression analysis between pesticide usage provided by the United States Department of Agriculture (USDA) and climate variations in several US locations, with climate data provided by the national oceanic atmospheric administration (NOAA). The per acre pesticide usage average cost for corn, cotton, potatoes, soybeans and wheat were found to increase as precipitation increases. Similarly, the pesticide usage average cost for corn, cotton, soybean, and potatoes also increases as temperature increases, while the pesticide usage cost for wheat decreases [56]. The main impact of climate change on chemical control will be in the cultural realm due to the fact that the entire humanity is suffering the consequences of anthropogenic activity in the process of exploiting the resources of the planet will raise awareness that this activity must be conducted in a sustainable way. The society will certainly exert pressure for the use of non-chemical methods to control plant diseases [5].

One of the direct consequences of climate change in the pathogen-host relationship is the genetic resistance of plants to diseases. Many changes in plant physiology can alter the resistance mechanisms of cultivars obtained by both traditional and genetic engineering methods.[41] Several studies provide evidences of these alterations, such as significant increases in photosynthetic rates, papillae production, silicon accumulation in appressorial penetration sites, higher carbohydrate accumulation in leaves, more wax, additional epidermal cell layers, increased fiber content, reduction in nutrient concentration and alteration in the production of resistance-related enzymes [19, 32].

Paoletti \& Lonardo [33] conducted one of the few studies to verify the effects of increased $\mathrm{CO}_{2}$ concentration on disease control by using resistant cultivars. Many changes in host physiology can potentially enhance plant resistance. However, the greatest threat to genetic resistance is the acceleration of pathogen cycles, which can be affected during all life cycle by increased $\mathrm{CO}_{2}$ concentrations $[3,11]$. Some studies revealed that in spite of a delay in the initial development and a reduction in host penetration, the established colonies develop faster. The increased fecundity of the pathogen, associated with a favorable microclimate within enlarged canopies, favors the occurrence of epidemics [40]. There is practically no information on the impacts of climate change on plant disease biological control. The few results obtained focus on climate change impacts on the composition and dynamics of the microbial community of the phyllosphere and the soil, which can be very important for plant health.

\subsection{Effect of Climate Change on Agricultural Pests and Diseases}

Climate change poses a significant threat to the control of pests and disease invasions. These "pests and diseases" include insects, plant diseases, and invasive weeds. As the climate variables continue to change, new pests and diseases may become able to invade previously uninhabitable. Climate factors that aid in pest and disease invasions are mostly temperature related and include increasing average temperatures, warmer winter minimum temperatures, changes in precipitation patterns, and water shortages [33].

Some crops like soybean and cowpea can serve as an alternative host for the pathogen. If warmer winters allow pathogens to move northward, and create a greater impact on the spread of the disease in most crops (Figure 5). As illustrated in figures 5, 6, 7 climate change significantly affects the aggressiveness of agricultural pest and diseases.

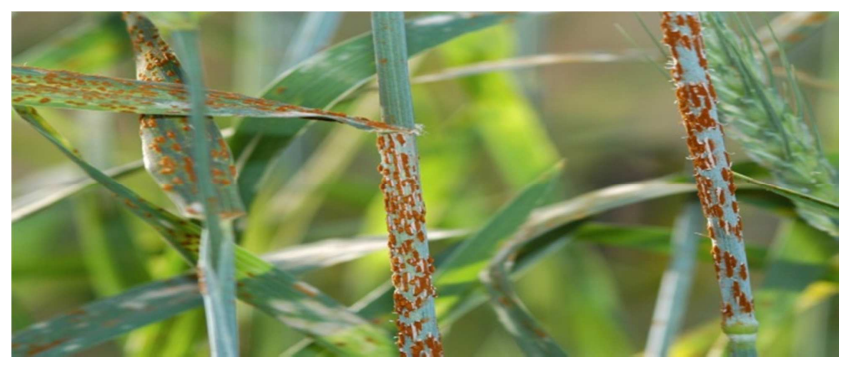

Figure 5. Rice blast caused by severe weather fluctuations [31].

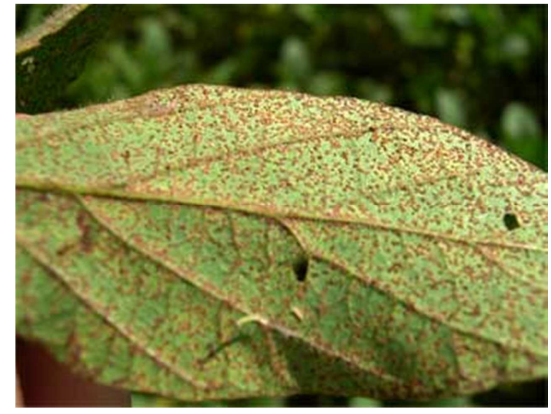

Figure 6. Asian soybean rust caused by extreme hot condition [17]. 


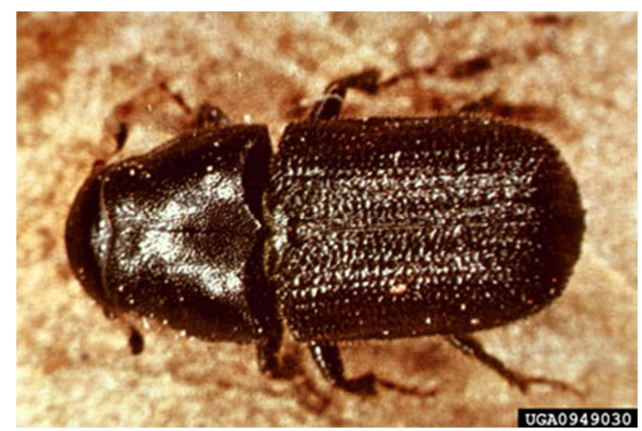

Figure 7. Many invasive insects are range-limited by cold temperatures [6].

\subsection{Origin of Pests and Diseases}

Some crop diseases and pests are native to a community or region, while others originate from other regions of the continent or world. In their native areas, potential pest species are kept under control by predators and other ecosystem processes [8]. However, once introduced to a different region, these pests and diseases may no longer have natural predators or other environmental variables to control their population size. Climate change is aiding these invasions by widening the "invasion niche," or the set of environmental conditions under which pests can successfully invade [54].

\subsection{Examples of Pest and Disease Invasion}

Threats due to climate change resulting from increasing temperatures contribute to a pole ward migration or expansion of the ranges of many organisms [13]. The average annual temperatures have been modeled to increase by up to $4.5^{\circ} \mathrm{C}$. Additionally, winter minimum temperatures may increase by up to $2.4^{\circ} \mathrm{C}$ in that same window [21]. This will likely result in an increased amount of new pest and disease species, as cold winter minimums have historically limited the ranges of the many pests and diseases

\section{Insect Pests}

Milder winters have been shown to increase the survival of many frost-sensitive insects [2] 2002). Increasing temperatures also allow for higher rates of growth and reproduction in insect herbivores [17]. Studies on aphids and moths have shown that increasing temperatures can enable insects to reach their minimum flight temperature sooner, aiding in increased dispersal capabilities [6]. Many studies have shown the northward expansion or shift of insect ranges, such as Edith's checker spot butterfly or the mountain pine beetle, to be correlated with increasing temperatures [39]. We can expect from insect pests in light of climate change some positive physiological responses to rising temperatures that allow for faster insect growth and movement. Furthermore, milder winters will allow for earlier insect growth and a reduction in overwinter deaths. The expansion or shift in ranges coupled with an increase in growth and numbers will likely increase insect invasions.

\subsection{Diseases Vectors}

Crop diseases can be animal, fungal, bacterial, or viral in origin and are often spread through an insect vector. Fungal infections are also common and can spread via spores carried by the wind. Dispersal plays a crucial role in the spread of crop disease, and anthropogenic activities have been found to contribute to the spread of sudden oak death. An increase in severe weather events such as hurricanes may also catalyze the spread of crop diseases such as soybean rust across continents or oceans $[21,56]$. Climate change can also aid in the dispersal of plant and crop disease. A local increase in summer precipitation due to climate change has been found to be responsible for the increase and spread of needle blight in British Columbia [19].

\subsection{Weeds}

Climate change is expected to increase the range, or "damage niche of many weed species. Some research suggests that the composition of invasive weed communities will be fundamentally altered by the end of the century under increasing temperature scenarios, with new weed species entering communities as a result of geographic range shifts $[16,40]$. For example, the range of the Striga species a maize weed is expected to increase to more in sub-Saharan Africa where there is intensive maize farming under a cultural disease control system, due to climate change [9, 42, 53].

The effects of climate change on weed/plant interactions are likely to vary by region and crop type. Understanding of the underlying physiological mechanisms responses to such factors is needed to address these effects. Since the interactions between crops and weeds are "balanced" by various environmental factors, local changes in these factors may tip the scale towards either crop or weed [1, 15]. Furthermore, as the geographic distribution of weed species changes, so will the community composition, posing both challenges and opportunities for invasion control. When the invasion of new weed species can be detected, efforts can be made in advance to prevent and control their establishment $[25,42]$.

\subsection{How Climate Change Affects Crop Pests and Diseases}

Elevated carbon dioxide and higher temperatures may act in a synergistic or opposing manner depending on the pest or pathogen concerned. The result of these changes cannot be foreseen as yet and waiting for the visual appearance of a pest or disease to initiate action, is the only remaining option. Organizing manual surveys to cover all major crop pests and diseases will be very costly and nearly impossible. Under these circumstances, spore and insect trap data can assist in anticipating incidences of pests and diseases [25]. A network spore and insect trapping centers to cover all major irrigated and rain-fed crops and their pests and diseases need to be set up. To ensure the network include major irrigated crops with minimum stations, delineated homogenous rainfall zones and crop-climate zones need to be taken into account [47].

Summation of the mean air temperatures above a specified 
base value, known as accumulated degree-days, has been useful for anticipating the incidence of many crop pests and diseases. To overcome the unsuitability of calendar dates and to begin calculations, the concept of biofix is used. For a pest or a disease, biofix date can mark the beginning of sustained trapping of insects or disease spores [29]. It is crucial to measure the economic threshold level (ETL), the insect density at which control operations must begin to prevent crop loss from exceeding the cost of control operations. Economic injury level (EIL) is the insect density at which crop loss is more than the cost of control operations and varies with pests, crops, and their growth stages. It is recommended to be taken as $75 \%$ of EIL [29]. Similarly, in the case of diseases, it is important to note the critical disease level (CDL), which is the point in time before which application of fungicides is not required and after which will be ineffective. Thus, for integrated management of pests and diseases using spore and insect trap data, it is necessary to lay down the ETL and CDL criteria for essential crop pests and diseases respectively [29, 33].

The higher nighttime temperature will reduce the duration of leaf-wetness and result in lesser disease incidence. Biological control of a pest or disease through the introduction of their natural enemies from other regions will become more effective, and warm temperatures will favour their quick establishment and development [5, 57]. Forewarnings based on current crop position and expected weather are most effective when there is a time lag between the onset of favourable conditions and the manifestation of pest or disease affliction. In addition, an initial inoculum is detected in insect or spore traps and the organism's phenological development is amenable to a calculation by the accumulated degree days approach above a base value. The effectiveness of forewarnings of pests and diseases is maximal over large mono-cropped areas and minimal in situations of variegated cropping [20].

\subsection{Solutions that Exist to Address Climate Change and Pests}

Integrated pest management lies at the center of insect, disease, and weed control. The combination of farming strategies, biological control agents, and necessary pesticide and herbicide use has helped farmers address pest problems using a variety of methods. Climate change may make integrated pest management (IPM) solutions less effective and harder to implement. The spread of pests and disease through human vectors will continue to become a problem, especially as they become more tolerant of environmental conditions $[11,36]$.

Increasing resistance to pesticides among invasive insects is a problem for farmers and the effectiveness of current IPM and other pest management strategies. For example, Liu [26] showed that invasive populations of the potato Psyllid have a higher resistance to certain pesticides than the native populations [30, 47]. Plant growth responses to increasing $\mathrm{CO}_{2}$ will aid in herbicide resistance by increasing leaf thickness and decreasing stomatal openings and soil nutrient uptake, which could make plants less likely to absorb applied herbicides. As a result, IPM solutions will have to adapt to these problems. Biological control agents can be effective against insect or weed populations that are resistant to pesticides or herbicides. The establishment of hedgerows containing native vegetation can aid in the establishment of beneficial insect and plant communities near crops to aid in biological control.

\subsection{What We Need to Understand to Adapt Management to Climate Change}

Farming practices such as cleaning equipment between crop uses can help to minimize the spread of diseases or pests, and planting strategies such as changing planting times can counter weed growth [16].

For growers we need to adapt early warning systems for within-season tactical decision making. How to construct longer-term (season or longer) support for decision making. For plant breeders and pesticide developers there is need to understand what diseases/weeds/pests to prioritize where. For policy makers, stakeholders/ donors the need to understand what the important problems are for investment in the future.

How financial tools can buffer farmers from increased variability in natural systems and new biofuels systems in addition to the distribution of resistance genes

\section{Future Perspectives}

If food production has to increase by $50 \%$ in the next 50 years from the declining land resources, this will need a sustainable and huge investment of capital, time and human resources. In common with the past achievement of world agriculture that gave rise to green revolution to save millions of population from starvation, the main component of the solution in the future will be from a technology driven platform. This technology will need to produce, process, distribute and market food that is sufficient, safe and nutritious to meet the dietary needs and preferences of the world human population, without affecting the sustainability of the natural environment. There has been limited empirical research on plant diseases/vectors under field conditions that realistically mimic climate change and this greatly hinders the development options to enhance sustainable crop adaptation to biodiversity and conservation or integrated pest and diseases management (IPDM) under climate change. From the point of view of global food security there must be a shift in paradigm from impact assessment to developing an adaptation and mitigation strategies for a viable control options [56].

Two main areas are of interest are important for investigation, that involves evaluation under climate change the efficacy of integrated control; chemical, biological disease resistance cultivars, sand then to include future climate situations in all research driven projects on new technologies and strategies. Transgenic technology in particular must take into consideration integrated disease management within the framework of food security. 


\section{Conclusion}

Climatic change has attracted world interest for common mobilization to address the problem. It has become a global concern and a threat to food crop management to tame hunger worldwide. There are many actors, and advocacy initiatives in most countries to save the environment and increase food productivity. The initiative drive must be motivated by a well-developed climate information disease risk management system. There is the need for a high throughput data base system. This takes into account the historical climate data in a defined region, seasonal climate forecast, the different models for crop yield, crop-disease risk, plant disease model, the microclimate data and the economic input.

The impact of climate change on plant diseases is becoming a serious threat to food biosecurity and therefore requires a more multi-disciplinary research approach to address the problem. The effects of climate change could result from more frequent and more intense extreme weather events or from the changing temperatures and precipitation patterns. Agriculture-based livelihood systems remains one of the most affected dimensions of global food security and faces immediate risk of increased crop failure, new patterns of pests and diseases. Although the issues on climate change have developed rapidly in the last few decades, there are still some gaps in information, thereby necessitating investigation. Interactions with global change drivers influence the prediction and the management of climate change impacts on planet health. The models of plant disease development can under different forms of climate change, requiring different management strategies based on more participatory approaches. An understanding of climate change effect on our crops will support IPM strategies for sustainable crop production and food biosecurity. More insight on how climatic oscillation affects the host-pathogenvector interaction, needs more understanding and greater attention than it has hitherto received in order to put in place a robust disease pest management control strategy. The earth's climate has always changed in response to oscillation in the cryosphere, hydrosphere, biosphere and atmospheric factors interacting together. It is therefore widely understood that human activities are now increasingly having a negative influence in the global climate change.

\section{References}

[1] Agrios GN. (2004). Plant pathology. 5 ed. London: Elsevier, 922p.

[2] Bale JS, Masters GJ, Schneider P. (2002). "Herbivory in global climate change research: direct effects of rising temperature on insect herbivores." Global Change Biology 8 (1): $1-16$.

[3] Bergot M, Cloppet E, Perarnaud V, Deque M, Marcais B, Desprez-Loustau ML. (2004). Simulation of potential range expansion of oak disease caused by Phytophthora cinnamomi under climate change. Global Change Biology, 10: 1539-1552.
[4] Boag B, Crawford JW, Neilson R. (1991). The effect of potential climatic changes on the geographical distribution of the plant-parasitic nematodes Xiphinema and Longidorus in Europe. Nematologica, 37: 312-323.

[5] Boland GJ, Melzer MS, Hopkin A, Higgins V, Nassuth A. (2004). Climate change and plant diseases in Ontario. Canadian Journal of Plant Pathology-Revue Canadienne de Phytopathologie, 26: 335-350.

[6] Booth TH; Jovanovic T, Old KM, Dudzinski MJ. (2000). Climatic mapping to identify high-risk areas for Cylindrocladium quinqueseptatum leaf blight on eucalypts in mainland South East Asia and around the word. Environmental Pollution, 108: 365-372.

[7] Bradley BA Oppenheimer P, Stone RS. (2009). "Climate change and plant invasions: restoration opportunities ahead?" Global Change Biology 15 (6): 1511-1521.

[8] Braga MR, Aidar MPM, Marabesi MA, Godoy JRL, (2006). Effects of elevated $\mathrm{CO}_{2}$ on the phytoalexin production of two soybean cultivars differing in the resistance to stem canker disease. Environmental and Experimental Botany. 58: 85-92.

[9] Cayan DE,. Maurer R and Cooke O. (2008). "Climate change scenarios for the California Region." Climatic Change 87 (0): 21-42.Chakraborty S, Datta S (2003). How will plant pathogens adapt to host plant resistance at elevated $\mathrm{CO}_{2}$ under a changing climate? New Pathologist, 159: 733-742.

[11] Chakraborty S, Pangga IB (2004). Plant disease and climate change. In: Gillings M.; Holmes A, (ed.) Plant Microbiology. London: Bios Scientific, p. 163-180.

[12] Chen CC, McCarl BA. (2001). An investigation of the relationship between pesticide usage and climate change. Climatic Change, 50: 475-487.

[13] Coakley SM, Schern H, Chakraborty S (1999). Climate change and plant disease management. Ann. Rev. Phytopatholo. 37: 399-426.

[14] Eastburn DM, McElrone AJ, Bilgin DD (2011). Influence of atmospheric and climatic change on plant-pathogen interactions. Plant Pathol. 60: 54-59.

[15] Elad Y, Pertot I (2014). Climate change impacts on plants on plant pathogens and plant diseases. J. Crop Improve, 28: 99-139.

[16] Evans N, Baierl A, Semenov MA, Gladders P, Fitt BDL. (2008). Range and severity of plant disease increased by global warming. Journal of the Royal Society, 5: 525-531.

[17] Faynewbery AQ, Bruce DL. Fitt P (2016). Modelling impacts of climate change on arable crop diseases: progress, challenges and applications. Current Opinion in Plant Biology. 32: 101-109.

[18] Garrett KA.; Dendy SP, Frank EE, Rouse MN, Travers SE. (2006). Climate change effects on plant disease: genomes to ecosystems. Annual Review of Phytopathology, 44: 489-509.

[19] Huang YJ, Evans N; Li ZQ, Eckert M, Chèvre AM, Renard M, Fitt BDL (2006). Temperature and leaf wetness duration affect phenotypic expression of rlm6-mediated resistance to Leptosphaeria maculans in Brassica napus. New Phytologist, 170: $129-141$

[20] IPCC (2007). Climate change 2007: the physical science basis. Geneva: IPCC, 2007. 996p. (assessment report, 4). 
[21] Juroszek P, von Tiedemann A. 2015. Linking Plant Disease Models to Climate Change Scenarios to Project Future Risks of Crop Diseases: A Review. Journal of Planbt Disease and Protection. 122: 3-15.

[22] Karnosky DF, Percy KE, Xiang BX, Callan B, Noormets A, Mankovska B, Hopkin A, Sober J, Jones W, Dickson RE, Isebrands JG. (2002). Interacting elevated $\mathrm{CO}_{2}$ and tropospheric $\mathrm{O}_{3}$ predisposes aspen (Populus tremuloides Michx.) to infection by rust (Melampsora medusae f. sp tremuloidae). Global Change Biology, 8: 329-338.

[23] Kobayashi T, Ishiguro K, Nakajima T, Kim HY, Okada M, Kobayashi K (2006). Effects of elevated atmospheric $\mathrm{CO}_{2}$ concentration on the infection of rice blast and sheath blight. Phytopathology, 96: 425-431.

[24] Krupta S, McGrath MT, Andersen CP, Booker FL, Burkey KO, Chappelka AH, Chevone BI, Pell EJ, Zilinskas BA (2000). Ambient ozone and Plant Health. Plant Disease 85: 412.

[25] Li F, Kang S, Zhang J, Cohen S. (2003). Effects of atmospheric $\mathrm{CO}_{2}$ enrichment, water status and applied nitrogen on water- and nitrogen-use efficiencies of wheat. Plant and Soil, 254: 279-289.

[26] Liu D, and JT. Trumble (2007). "Comparative fitness of invasive and native populations of the potato psyllid (Bactericera cockerelli)." Entomologia Experimentalis et Applicata 123 (1): 35-42.

[27] Lichou J, Myrin JF, Breniaux D (2000). First report of brown rot caused by Monilinia fructicola in peach orchards in France. Phytoma, 47: 22.

[28] Logan JA and Powell JA (2001). Ghost forests, global warming, and the mountain pine beetle. Am Entomol 47: 160-73.

[29] Loladze I. (2002). Rising atmospheric $\mathrm{CO}_{2}$ and human nutrition: toward globally imbalanced plant stoichiometry? Trends in Ecology \& Evolution, 17: 457-461.

[30] Matthew P. Daugherty G, Platter J 2017. Conflicting Effects of Climate and Vector Behavior on the Spread of a Plant Pathogen, Phytobiomes). DOI: 10.1094/PBIOMES-01-17-0004-R.

[31] Maud B, Biarnès V, Jeuffro MF. (2017). Impact du climat et des maladies sur les rendements du poids : quelles perspectives avec le changement climatique Oilseeds and fat Crops and LipidsOCL 2017, 24 (1) D103 ?

[32] Mboup M, Bahri B, Leconte M, De Vallavieille-Pope C, Kaltz O, Enjalbert J. (2012). Genetic structure and local adaptation of European whaet yellow rust populations: the role of temperature-specific adaptation. Evol. Appl. 5: 341-352.

[33] Mcelrone AJ, Reid CD Hoye KA, Hart E, Jackson RB (2005). Elevated $\mathrm{CO}_{2}$ reduces disease incidence and severity of a red maple fungal pathogen via changes in host physiology and leaf chemistry. Global Change Biology, 11: 1828-1836.

[34] McDonald AS, Riha S and Puto C. (2009). "Climate change and the geography of weed damage: analysis of u.s. maize systems suggests the potential for significant range transformations." Agriculture, Ecosystems \& Environment $130(3-4): 131-140$.

[35] Mitchell CE, Reich PB, Plumb T. (2003). "Effects of elevated $\mathrm{CO}_{2}$, nitrogen deposition, and decreased species diversity on foliar fungal plant disease." Global Change Biology 9 (3)
[36] Osswald WF, Fleischmann F, Heiser I. (2006). Investigations on the effect of ozone, elevated $\mathrm{CO}_{2}$ and nitrogen fertilization on host-parasite interactions. Summa Phytopathologica, 32s, s111-s113.

[37] Pangga IB, Chakraborty S, Yates D. (2004). Canopy size and induced resistance in Stylosanthes scabra determine anthracnose severity at high $\mathrm{CO}_{2}$. Phytopathology, 4: 221-227.

[38] Paoletti E, Lonardo V. (2001). Seiridium cardinale cankers in a tolerant Cupressus sempervirens clone under naturally $\mathrm{CO}_{2}-$ enriched conditions. Forest Pathology, 31: 307-311.

[39] Parmesan C, (2006). "Ecological and evolutionary responses to recent climate change." Annual Review of Ecology, Evolution, and Systematics 37 (1): 637-669.

[40] Pellegrino C, Gullino ML, Garibaldi A, Spadaro D. (2009) First report of brown rot of stone fruit caused by Monilinia fructicola in Italy. Plant Dis. 93: 668.

[41] Percy KE, Awmarck CS, Lindroth RL, Kubiske ME, Kopper BJ, Isebrands JG, Pregitzer KS, Hendrey GR, Dickson RE, Zak DR, Oksanen E, Sober J, Harrington R, Karnosky DF. (2002). Altered performance of forest pests under atmospheres enriched by $\mathrm{CO}_{2}$ and $\mathrm{O}_{3}$. Nature, 420: 403-407.

[42] Pritchard SG, Amthor JS. (2005). Crops and Environmental Change. Binghamton: Food Products Press. 421p.

[43] Prospero S, Grunwald NJ, Winton LM, Hansen EDM. (2009). Migration patterns of the emerging plant pathogen Phytophthora ramorum on the West Coast of the United States of America. Phytopathology, 99, 739-749.

[44] Rezácová V, Blum H, Hrselová H, Gamper H, Gryndler M. (2005). Saprobic microfungi under Lolium perenne and Trifolium repens at different fertilization intensities and elevated atmospheric $\mathrm{CO}_{2}$ concentration. Global Change Biology, v. 11, p. 224-230, 2005.

[45] Richerzhagen D, Racca P, Zeuner T, Kuhn C, Falke K, Kleinhenz b, Hau B. (2011). Impact of climate on the temporal and regional occurence of Cercospora leaf spot in Lower saxony. J. Plant Dis. Prot. 118: 168-177.

[46] Rosenzweig CA, Iglesias R and Cooke P. (2001). "climate change and extreme weather events; implications for food production, plant diseases, and pests." global change \&amp; human health 2 (2): 90-104.

[47] Salinari F, Giosue S; Tubiello FN, Rettori A, Rossi V, Spanna F Rosenzweig C, Gullino ML. (2006). Downy mildew (Plasmopara viticola) epidemics on grapevine under climate change. Global Change Biology, v. 12, p. 1299-1307.

[48] Scherm H, Coakley SM. (2003). Plant pathogens in a changing world. Australasian Plant Pathology, v. 32, p. 157-165, 2003.

[49] Scherm H. (2004). Climate change can we predict the impacts on plant pathology and pest management? Canadian Journal of Plant Pathology, v. 26, p. 267-273, 2004.

[50] Siegenthaler U; Stocker TF, Monnin E, Luthi D, Schwander J, Stauffer B, Raynaud D, Barnola, JM, Fischer H, Masson-Delmotte V, Jouzel J. (2016). Stable carbon cycle-climate relationship during the late pleistocene. Science, v. 310, p. 1313-1317.

[51] Strange RN, Scott PR. (2005). Plant disease: a threat to global food security. Annual review of phytopathology, 43, p. 83-116. 
[52] Schneider RW, Hollier DD, Khan C. (2005). "First report of soybean rust caused by Phakopsora pachyrhizi in the continental United States." Plant Disease 89 (7): 774-774.

[53] Tiedemann AV, Firsching KH. (2000). Interactive effects of elevated ozone and carbon dioxide on growth and yield of leaf rust-infected versus non-infected wheat. Environmental Pollution, v. 108, p. 357-363.

[54] Woods AK, Coates D, Green TL. (2005). "Is an unprecedented
Dothistroma needle blight epidemic related to climate change?" Bioscience 55 (9): 761-769.

[55] von Tiedemann A, Firsching KH. (2000). Interactive effects of elevated ozone and carbon dioxide on growth and yield of leaf rust-infected wheat. Environ. Pollut. 108: 357-363.

[56] Vuuren DP, van; O'neill, BCO (2006). The consistency of IPCC's research scenarios to recent literature and recent projections. Climatic Change, v. 75, p. 9-46. 